Hip dysplasia

\section{Hip dysplasia and ultrasound imaging of whole populations: the precautionary principle revisited}

\section{Elbourne, C Dezateux}

\section{Screening for hip dysplasia in the United Kingdom requires some consideration}

$\mathrm{S}$ creening for developmental hip disorders has been with us for almost 40 years. Twenty years ago Cliff Roberton famously called it a "mess". ${ }^{1}$ The paper by Roovers et $a l^{2}$ published in this issue reports the findings of an observational study to determine whether a strategy of universal ultrasound screening carried out after the newborn period is "more effective" than a strategy based on clinical examination alone. Before considering the implications of this report for policy and practice, it is worth rehearsing some of the challenges facing those who have sought to evaluate this "mess" over the last 40 years.

Developmental dysplasia of the hip (DDH) refers to a spectrum of developmental hip disorders including partial or complete displacement of the femoral head from the acetabulum-that is, developmental displacement of the hip, previously called congenital dislocation of the hip $(\mathrm{CDH})$. Ultrasound imaging of the largely cartilaginous newborn hip, first introduced in the 1980s and pioneered by Graf, has contributed to a paradigm shift in what we mean by $\mathrm{CDH}$. Neonatal hip instability has become synonymous with the outcome it was meant to signal, and dysplastic or shallow hips in the newborn have been added to the disorders for which screening is considered desirable, despite there being only limited understanding of their significance for later hip development. ${ }^{3}$

When introduced in the 1960s, there was an expectation that early recognition through clinical screening combined with abduction splinting would prevent impaired hip growth and development, serious abnormalities of gait, and premature degenerative changes in the hip joint. To try to prevent these problems by seeking an early diagnosis seems a laudable endeavour. Not all good intentions, however, have their intended consequences.

Sackett et $a l^{4}$ suggest questions for clinicians (and policy makers) to ask when deciding whether or not to seek an early diagnosis. To the question about whether the burden of disability from the disease warrants action, the answer for DDH must be "yes", but only if the action actually helps. Answers to other important questions, including whether early diagnosis through screening really does lead to improved clinical outcomes and whether-at a population level-screening is associated overall with more benefit than harm, are less clear.

The extent to which the expectations of screening programmes have been met has been controversial and difficult to judge, due in part to the absence of a "gold standard" diagnostic test, failure to evaluate the effectiveness of abduction splinting before its widespread introduction, and a paucity of trials or high quality observational studies that have systematically followed screen positive and screen negative children for sufficient periods of time. With these caveats, what has been learnt from observational studies?

In Northern European populations, $\mathrm{CDH}$ affects about one in every 1000 children born. We have suggested that in the United Kingdom the number of children requiring at least one operative procedure for $\mathrm{CDH}$ has not fallen since screening was introduced, ${ }^{5}$ although this has not been the reported experience of other countries. ${ }^{67}$ Ultrasound screening programmes for DDH appear to detect a higher proportion of affected children, although false negative diagnoses are not entirely eliminated. ${ }^{8}$ However, this comes at a cost, namely abduction splinting rates of 50-70 per 1000 infants born, compared with an equivalent figure of 4-20 per 1000 for programmes based on clinical screening examination. A small price to pay, it has been argued, given the burden of DDH, except that avascular necrosis of the femoral head, a serious and iatrogenic complication of abduction splinting, affects just under $1 \%$ of those treated including those who are unaffected. ${ }^{9}$
Reduction of overtreatment is consequently an important goal to aspire to within universal ultrasound screening programmes. ${ }^{8}$ Hence the study by Roovers et al, ${ }^{2}$ which aims, by screening outside the newborn period, to deliver the benefits of ultrasound in terms of a higher detection rate while avoiding the disbenefits of overtreatment.

In their historical cohort study, a strategy of three ultrasound examinations undertaken at one monthly intervals from 1 month of age is compared with a study of clinical examination carried out in 1993. ${ }^{2}$ The authors report that ultrasound is more "effective" than clinical examination, citing fewer and earlier referrals, a higher detection rate, lower false negative rate, and fewer admissions for inpatient treatment than the clinically screened population. However, despite this, Roovers et al reported that the ultrasound strategy was associated with $4.6 \%$ of children receiving treatment, a comparable proportion to that reported from other ultrasound programmes. It would appear then that overtreatment remains an issue even with deferred age at screening.

Drawing inferences from the data presented from this study is complicated by the historical comparison group. As the authors point out, thresholds for hospital admission as well as treatment are likely to have changed quite considerably over the interval between the earlier study of clinical screening and the later study of ultrasound. An additional issue is what is being detected. With ultrasound, 52 per 1000 (most of whom are treated) are reported as affected compared with 35 per 1000 in the earlier clinical study. The diagnostic conundrum rears its head and-somewhat surprisingly and despite an exemplary strategy to follow all screened children to 8 months of agewe are left to infer the false positive rates for each strategy with referral rates-reported as lower in the ultrasound arm-presented as some proxy for these. But is this really the case and is it fair to disregard the costs in their broadest sense of repeated examinations of the initially borderline cases in the community? Clegg et a $l^{10}$ have succeeded in achieving one of the lowest abduction splinting rates in a universal ultrasound programme by exactly this strategy of repeated ultrasounds for borderline cases. However, this may entail up to eight visits before a treatment decision is made, with some $20 \%$ dropping out along the way.

The most scientifically rigorous way to assess the evidence of the effectiveness of a screening policy is a randomised controlled trial (RCT). Trials can 
and have been conducted in this field. For instance, we and colleagues have evaluated the clinical effectiveness, ${ }^{11}$ cost effectiveness (A Gray, D Elbourne, C Dezateux et al, unpublished work), and implications for mothers ${ }^{12}$ of a policy of ultrasound screening for babies already screened positive on the routine clinical screen. The results suggest that ultrasound imaging used in this way allows the initial screening diagnosis to be refined, leading to a reduction in abduction splinting rates which is not associated with an increase in abnormal hip development or higher rates of operative treatment by 2 years of age, or significantly higher costs or psychosocial problems for mothers. This trial did not, however, consider the role of ultrasound screening for all newborn babies.

Two randomised trials have addressed primary screening. ${ }^{73}$ Rosendahl et al reported that universal ultrasound was associated with a higher proportion receiving abduction splinting and follow up because of borderline findings, but a lower proportion with "late" subluxation or dislocation. In a subsequent trial, Holen et $\mathrm{al}^{7}$ compared universal ultrasound with high quality clinical screening and found that there was no statistically significant difference in the proportion with late presenting hip dysplasia. They recommended using ultrasound only in those with clinical hip instability or recognised risk factors.

If insufficient information is available from RCTs, decision models provide a complementary approach. On the basis of a recent such analysis based largely on observational studies, Dezateux et al ${ }^{9}$ concluded that "ultrasound based screening strategies appeared to be most sensitive and effective but are associated with the greatest risk of potential adverse iatrogenic effects arising in unaffected children."

So does the paper by Roovers et $a l^{2}$ require a rethink of existing screening policy in the United Kingdom? ${ }^{14}$ The answer is no, but the challenge facing the United Kingdom will be how to implement high quality clinical screening services and to measure what we do.

Arch Dis Child Fetal Neonatal Ed

2005;90:F2-F3.

doi: $10.1136 /$ adc. 2004.052878

\section{Authors' affiliations}

D Elbourne, Medical Statistics Unit, London School of Hygiene and Tropical Medicine, London WCIE 7HT, UK

C Dezateux, Institute of Child Health, London WCIN IEH, UK

Correspondence to: Professor Elbourne, Medical Statistics Unit, London School of Hygiene and Tropical Medicine, Keppel Street, London WCIE 7HT, UK; diana.elbourne@ Ishtm.ac.uk

$C D$ is a member of the child health group of the National Screening Committee. This article is written in a personal capacity.

\section{REFERENCES}

1 Roberton NRC. Screening for congenital hip dislocation. Lancet 1984; i:909-10.

2 Roovers EA, Boere-Boonekkamp MM Castelein RM, et al. Effectiveness of ultrasound screening for developmental dysplasia of the hip. Arch Dis Child Fetal Neonatal Ed 2005;90.
3 Feldman DS. How to avoid missing congenital dislocation of the hip [comment]. Lancet 1999:354:1490-1.

4 Sackett DL, Haynes RB, Guyatt GH, et al. Clinical epidemiology: a basic science for clinical medicine. Little, Brown and Company: Boston 1991.

5 Godward S, Dezateux C. Surgery for congenital dislocation of the hip in the UK as a measure of outcome of screening. Lancet 1998;351:1149-52.

6 Chan A, Cundy PJ, Foster BK, et al. Late diagnosis of congenital dislocation of the hip and presence of a screening programme: South Australian population-based study. Lancet 1999;354:1514-17.

7 Holen KJ, Tegnander A, Bredland T, et al. Universal or selective screening of the neonatal hip using ultrasound? J Bone Joint Surg 2002;84:886-90.

8 von Kries R, Ihme N, Oberle D, et al. Effect of ultrasound screening on the rate of first operative procedures for developmental hip dysplasia in Germany. Lancet 2003;362:1883-7.

9 Dezateux C, Brown J, Arthur R, et al. Performance, treatment pathways, and effects of alternative policy options for screening for developmental dysplasia of the hip in the United Kingdom. Arch Dis Child 2003:88:753-9.

10 Clegg J, Bache CE, Raut VV. Financial justification for routine ultrasound screening of the neonatal hip. J Bone Joint Surg [Br] 1999:81:852-7.

11 Elbourne D, Dezateux C, Arthur R, et al. Ultrasonography in the diagnosis and management of developmental hip dysplasia (UK Hip Trial): clinical and economic results of a multicentre randomised controlled trial. Lancet 2002;360:2009-17.

12 Gardner F, Dezateux C, Elbourne D, et al. The hip trial: psychosocial consequences for mothers of using ultrasound to manage infants with developmental hip dysplasia. Arch Dis Child Fetal Neonatal Ed 2005;90.

13 Rosendahl K, Markestad T, Lie RT. Ultrasound screening for developmental dysplasia of the hip in the neonate: the effect on treatment rate and prevalence of late cases. Pediatrics 1994;94:47-52.

14 Elliman DA, Dezateux C, Bedford HE. Newborn and childhood screening programmes: criteria, evidence, and current policy. Arch Dis Child 2002;87:6-9.

\section{Etamsylate for prevention of periventricular haemorrhage}

\section{R W Hunt}

\section{A perspective on the paper by Schulte et al (see page 31)}

D espite the many advances of newborn intensive care over the past 20 years, periventricular haemorrhage $(\mathrm{PVH})$ remains a significant cause of morbidity and mortality for the preterm infant. About 15\% of infants with birth weight less than $1500 \mathrm{~g}$ develop $\mathrm{PVH}^{1}{ }^{1}$ and its presence significantly increases the risk of neurodevelopmental impairment.

New insights have been gained into the pathophysiology of PVH. The germinal matrix, a fragile network of blood vessels lining the ventricular system, is prone to bleeding in the preterm infant. The beagle puppy model of PVH has provided insight into our current understanding of the pathogenetic role of ischaemia and reperfusion. ${ }^{2}$ In the human preterm infant, depression of cerebral blood flow, associated with initial reduction in myocardial performance and presence of a patent ductus arteriosus, provides an environment in which ischaemia and reperfusion are likely, and PVH occurs more commonly under these circumstances. $^{3}$

The absence of one unifying aetiological pathway to PVH has left those who practice neonatal medicine without a specific therapeutic strategy that has the capacity to decrease the incidence of PVH. Many therapeutic agents have been investigated over the past 30 years, in the hope of developing such a strategy.

One such agent is etamsylate (diethylammonium 1,4-dihydroxy-3-benzenesulphonate). This non-steroidal drug was shown to be effective in reducing blood loss from menorrhagia ${ }^{4}$ and after trans-urethral resection of the prostate. ${ }^{5}$ The benefits of etamsylate in reduction of bleeding in these settings led to the postulate that it may be of benefit in reducing $\mathrm{PVH}$.

The precise mechanism of action of etamsylate is unknown. It has been shown to reduce bleeding time and 
blood loss from wounds. ${ }^{6}$ This appears to relate to increased platelet aggregation mediated by a thromboxane $\mathrm{A}_{2}$ or prostaglandin $F_{2 \alpha}$ dependent mechanism. ${ }^{78}$ It has also been associated with decreased concentrations of 6-oxoprostaglandin $F_{1 \alpha}$, a stable metabolite of prostacyclin. Prostacyclin is a potent vasodilator, and may be implicated in reperfusion; it is also a disaggregator of platelets.' Whereas prostaglandins themselves may have a role in regulating cerebral blood flow, etamsylate appears to have no effect on cerebral blood flow. ${ }^{10}$ When tested in the beagle puppy, ${ }^{11}$ etamsylate reduced $\mathrm{PVH}$ and its administration was associated with reduced levels of 6-oxoprostaglandin $F_{1 \alpha}$. Etamsylate was also thought to stabilise capillaries, reinforcing capillary membranes by polymerising hyaluronic acid. ${ }^{12}$ No significant adverse effects have been related to the use of etamsylate in humans.

Etamsylate has been the subject of a number of clinical trials, and the first published trial ${ }^{13}$ did show some reduction in PVH in the etamsylate treated group. However, the distribution of haemorrhage was different between the etamsylate and placebo groups, and the overall mortality related to extensive PVH did not differ between the two groups. Two large multicentre randomised controlled trials followed, ${ }^{14} 15$ and the developmental outcome data from one of these trials is reported in the current edition. ${ }^{16}$ In the reporting of the early morbidity and mortality, these two large trials gave conflicting results. Benson et $a l^{14}$ reported that etamsylate reduced both incidence and extension of $\mathrm{PVH}$, although overall mortality was unaffected. The EC etamsylate trial group ${ }^{15}$ showed no such difference.

The key outcomes of any treatment in the perinatal period are mortality and long term morbidity. In fact, the etamsylate trials were among the first to recognise this important premise, which is why the reporting by Schulte et $a l^{16}$ of their long term neurodevelopmental outcomes is so important. One of the most impressive aspects of this report is a retention rate of subjects over a period of several years approaching $100 \%$, and the absence of confounding by interobserver error. Their finding of improved cognitive outcome in etamsylate treated infants is interesting, with etamsylate appearing to have a more protective effect on girls than boys, albeit in small numbers. However, when death and significant impairment (general cognitive index $<70$ ) are combined, there is no significant difference between infants treated with etamsylate and those who received placebo.
A systematic review of randomised controlled trials of etamsylate (including data from Schulte et al, giving a total of over 500 infants) suggests a reduction in the risk of any PVH in preterm infants treated with etamsylate (risk rate (RR) 0.78, 95\% confidence interval (CI) 0.63 to 0.97 ), but no significant difference in the risk of grade 3 or 4 PVH (RR 0.55, 95\% CI 0.27 to 1.12 ) and more importantly, no overall reduction in mortality or longer term neurodevelopmental or neurosensory impairment. ${ }^{17}$ A similar message came out of the systematic review of prophylactic indomethacin, with promise of short term benefit but no significant improvement in mortality or longer term outcomes. ${ }^{18}$ At present, the randomised controlled trials of etamsylate have not shown a significant improvement in either mortality or neurodevelopmental outcome. Consequently, clinical use of etamsylate cannot be recommended in the preterm population.

Long term neurodevelopmental follow up has rightly become the outcome measure of greatest interest in perinatal trials. But how long is long enough? In most cases, "long term" refers to an assessment at 2 years of age. To their credit, Schulte $e^{2}$ al ${ }^{16}$ report follow up at around 4 years of age. Are there subtle differences in neurodevelopmental performance that may not be measurable until much later in childhood, when more detailed psychometric testing is possible? If such differences were to exist, they may be clinically important, impinging on the child's ability to perform later in life. Follow up to school age is difficult, and rarely achieves the retention of a cohort managed by Schulte et al. ${ }^{16}$ Problems of cohort retention aside, the single most important barrier to the conduct of trials, with outcome assessment at a meaningful age of childhood, is the difficulty in acquiring funding that will allow staff to be employed until a trial's completion. Government and other funding bodies must be made aware of the importance of funding trials to meaningful completion, and the responsibility for imparting this message lies with us, the clinical researchers. Even longer term follow up (of the order of five or eight years) of preterm infants enrolled into trials in the perinatal period is an almost overwhelming prospect, but true differences in significant, albeit subtle, neurodevelopmental outcome may not be detectable until this stage.

Advances in neonatal neurology have also led us to a point where our understanding of perinatal brain injury has extended beyond the injury detectable by ultrasound alone. The more diffuse encephalopathy of prematurity is common and is characterised by injury to both white and grey matter, with reduction in volumes of these tissue types. ${ }^{19}$ This finding further challenges us to unravel the pathophysiology of preterm brain development and injury. Diffuse encephalopathy of prematurity may well be the reason why PVH does not always correlate well with neurodevelopmental outcome. The therapeutic strategies that optimise brain development in the preterm infant will undoubtedly by multifaceted. The potential benefit of strategies used in the perinatal period must continue to be evaluated by well constructed randomised controlled trials, the primary outcome measure of which is timely and meaningful long term neurodevelopmental outcome.

\section{ACKNOWLEDGEMENTS}

With thanks to Dr Susan Jacobs and Dr Peter Davis for their thoughtful comments on this manuscript.

\section{Arch Dis Child Fetal Neonatal Ed} 2005;90:F3-F5

doi: $10.1136 /$ adc. 2003.045625

Correspondence to: Dr Hunt, Department of Neonatal Medicine, Level 2, Royal Children's Hospital, Flemington Road, Parkville, VIC 3052, Australia; rod.hunt@rch.org.au

\section{REFERENCES}

1 Volpe JJ. Neurology of the newborn, 4th ed. Philadelphia: WB Saunders Company, 2001.

2 Ment LR, Stewart WB, Duncan CC, et al. Beagle puppy model of intraventricular haemorrhage. J Neurosurg 1982;57:219-23.

3 Kluckow M, Evans N. Low superior vena cava flow and intraventricular haemorrhage. Arch Dis Child Fetal Neonatal Ed 2000;82:F188-94.

4 Harrison RF, Campbell SA. A double-blind trial of ethamsylate in the treatment of primary and intrauterine induced menorrhagia. Lancet 1976;2:283-5.

5 Symes JM. The effect of dicynene on blood loss during and after transurethral resection of the prostate. Br J Urol 1975:47:203.

6 Vinazzer $\mathrm{H}$. Clinical and experimental studies on the action of ethamsylate on haemostasis and on platelet functions. Thromb Res 1980;19:783-91.

7 Okuma M, Takayama H, Sugiyama T, et al. Effects of etamsylate on platelet functions and arachidonic acid metabolism. Thromb Haemostas 1982;48:330-3.

8 Kowacs L, Falkay G. Etamsylate as inhibitor of prostaglandin biosynthesis in pregnant human myometrium in vitro. Experientia 1981;37:1182-3.

9 Rennie JM, Doyle J, Cooke RWI. Ethamsylate reduces immunoreactive prostacyclin metabolite in low birth weight infants with respiratory distress syndrome. Early Hum Dev 1986;14:239-44.

10 Rennie JM, Lam PKL. Effects of ethamsylate on cerebral blood flow velocity in premature babies. Arch Dis Child 1989;64:46-7.

11 Ment LR, Stewart WB, Duncan CC. Beagle puppy model of intraventricular hemorrhage: ethamsylate studies. Prostaglandins 1984;27:245-56.

12 Huguet B, Thomas J, Raynaud G. Action of cylonamine, a haemostatic drug, on capillary permeability and resistance. Therapie 1969;24:429-50.

13 Morgan MEl, Benson JWT, Cooke RWI. Ethamsylate reduces the incidence of periventricular haemorrhage in very low birthweight babies. Lancet 1981;2:830-1. 
14 Benson JWT, Hayward C, Osborne JP, et al. Multicentre trial of ethamsylate for prevention of perventricular haemorrhage in very low birthweight infants. Lancet 1986;2:1297-300.

15 The EC ethamsylate trial group. The EC randomized controlled trial of prophylactic ethamsylate for very preterm neonates: early mortality and morbidity. Arch Dis Child Fetal Neonatal Ed 1994;70:F201-5.
16 Schulte J, Osborne J, Benson JWT, et al. Developmental outcome of the use of etamsylate for prevention of periventricular haemorrhage in a randomised controlled trial. Arch Dis Child Fetal Neonatal Ed 2004;89.

17 Hunt R, Hey E. Ethamsylate for the prevention of morbidity and mortality in preterm or very low birth weight infants (Cochrane Review). Cochrane Library. Oxford: Update Software, in press.
18 Fowlie PW, Davis PG. Prophylactic intravenous indomethacin for preventing mortality and morbidity in preterm infants (Cochrane Review) Cochrane Library, Issue 4. Chichester: John Wiley \& Sons Ltd, 2003.

19 Inder TE, Wells SJ, Mogridge NB, et al. Defining the nature of the cerebral abnormalities in the premature infant: a qualitative magnetic resonance imaging study. J Pediatr 2003;143:171-9.

\section{IMAGES IN NEONATAL MEDICINE}

\section{Neonatal long lines: localisation with colour Doppler ultrasonography}

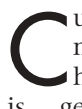

urrent guidelines are to avoid placement of neonatal long lines within the heart. ${ }^{1}$ Placement within the heart generally "excluded" radiologically. However, even with the benefit of contrast ${ }^{2}$ and digital ${ }^{3}$ radiography, the tips of long lines may not be adequately visualised. Standard two dimensional ultrasonography may assist in localising line tips in neonates, but the technique requires significant experience, and images are not optimal (fig 1A, B). We therefore investigated the use of colour Doppler to aid ultrasonographic line tip visualisation.

A Vygon 24 gauge catheter has an internal diameter of $0.3 \mathrm{~mm}$ (area approximately $0.0007 \mathrm{~cm}^{2}$ ). When flushed at $0.1 \mathrm{ml} / \mathrm{s}$, flow rate at the line tip is about $140 \mathrm{~cm} / \mathrm{s}$, well above usual venous flow rates. Using colour Doppler, the same line barely visible in fig $\mathrm{lA}, \mathrm{B}$, and masked by superior vena caval blood flow in fig $\mathrm{IC}$, becomes clearly visible when flushed with saline at about $0.1 \mathrm{ml} / \mathrm{s}$ (fig 1D).

We are not aware of any centres routinely using colour Doppler to aid ultrasonic detection of long line tip position in neonates. This technique potentially offers a simple, reliable method of localising line tips and should be put through further rigorous assessment.

A M Groves, C A Kuschel, M R Battin Newborn Services, National Women's Hospital, Claude Road, Auckland, New Zealand; malcolmb@adhb.govt.nz

Competing interests: none declared

\section{REFERENCES}

1 Wariyar UK, Hallworth D. Review of four neonatal deaths due to cardiac tamponade associated with the presence of a central venous catheter. London: Department of Health, 2001.

2 Odd DE, Page B, Battin MR, et al. Does radioopaque contrast improve radiographic localisation of percutaneous central venous lines? Arch Dis Child Fetal Neonatal Ed 2004;89:F41-3.

3 Evans A, Natarajan J, Davies CJ. Long line positioning in neonates: does computed radiography improve visibility? Arch Dis Child Fetal Neonatal Ed 2004;89:F44-5.

4 Ohki Y, Tabata M, Kuwashima M, et al.

Ultrasonographic detection of very thin percutaneous central venous catheter in neonates. Acta Paediatr 2000;89:1381-4.
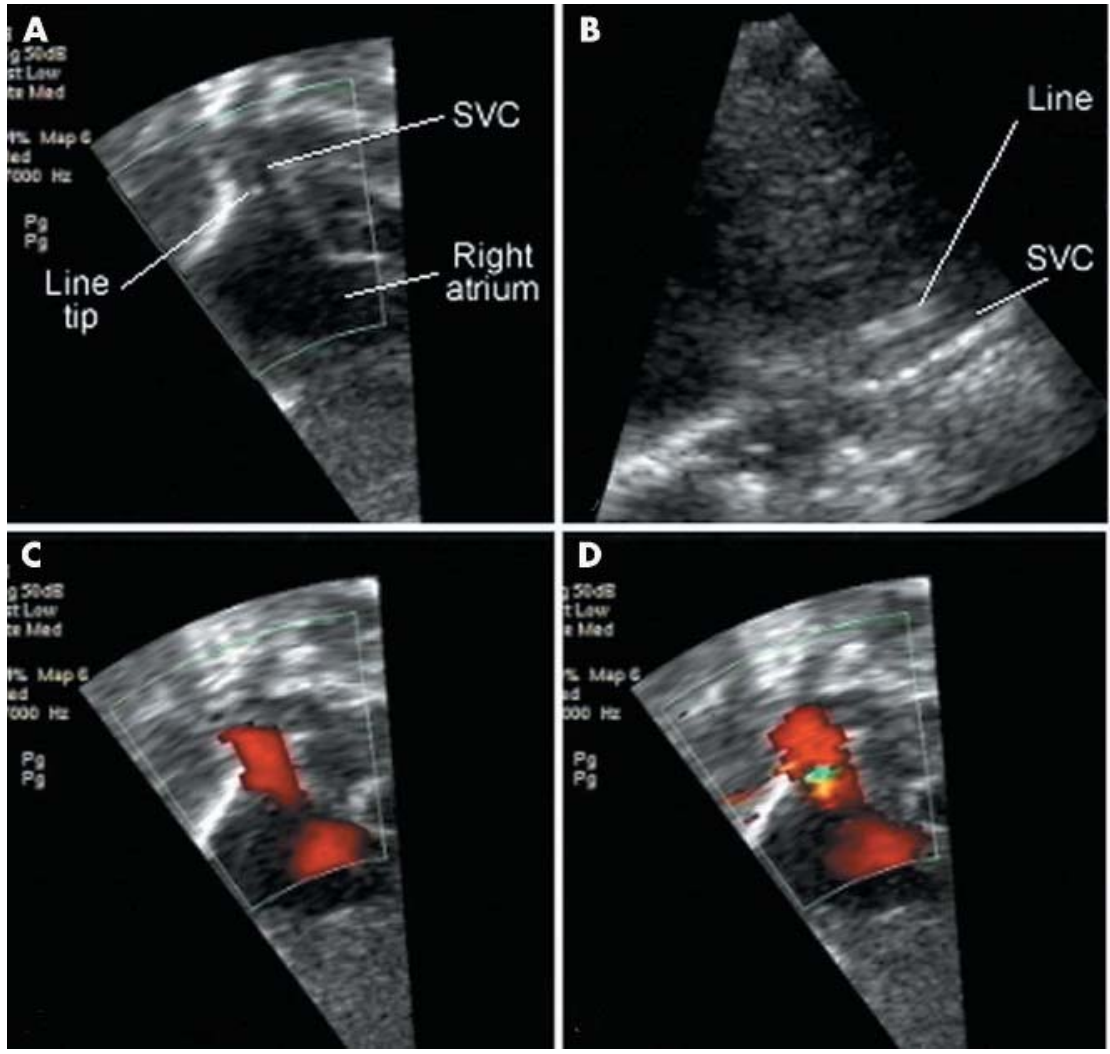

Figure 1 (A) Line tip entering right atrium on subcostal view; (B) line passing along superior vena cava (SVC) on parasternal view; (C) normal colour Doppler flow pattern in superior vena cava; (D) line tip "illuminated" by saline flush. 